\title{
The guidelines and principles for planning and design of road restraint systems
}

\author{
Marcin Budzyński ${ }^{1, *}$, and Marcin Antoniuk ${ }^{1}$ \\ ${ }^{1}$ Gdansk University of Technology, Faculty of Civil and Environmental Engineering, Gdansk, Poland
}

\begin{abstract}
The project RID 3A Road Safety Equipment (RoSE) implemented by the Gdansk University of Technology within the RID programme, aims to conduct a comprehensive study and analyses of different vehicle containment systems (PN-EN 1317) and types of support structures (PN-EN 12767) and their performance. Within the project an analysis will be conducted of available research reports and domestic and foreign experiences looking at road restraint systems and support structures applications. The paper will present a comparison of the guidelines and principles for the design and application of road restraint systems. Similarities and differences in the approach to different solutions will also be discussed. The above analyses will form the basis for the development of tools for selecting and applying road restraint systems in Poland.
\end{abstract}

\section{Introduction}

Road safety devices can be divided into two groups. Active devices are designed to handle the impact of out-of-control vehicles, including collisions and crashes. They are specifically designed to minimise the consequences of such events, especially those involving people (injury or death). Passive devices do not come into direct contact with vehicles involved in a crash or accident and are only used to organise and control road traffic, prevent disruptions to traffic and inform motorists and other road users in advance about safety risks or traffic delays. Safety barriers are active road safety devices and are used if the consequences of a crash or accident were greater than those caused by crashing into a barrier (e.g. hitting a tree). To ensure that barriers are effective, they must be designed to successfully handle vehicle impact because their main objective is to protect road users (and roadside users) from fatal injury. The paper presents the experience of other countries in planning and designing road safety devices.

\section{Active road safety devices}

These devices are primarily used to:

- physically prevent a vehicle from running off the road where this would be dangerous,

- physically prevent a vehicle from crossing into the path of oncoming vehicles,

- prevent a vehicle from colliding with permanent objects or obstacles on the road or roadside,

- secure "special" spots.

\footnotetext{
* Corresponding author: mbudz@.pg.edu.pl
} 
Safety barriers (as the basic active road safety device) should respond to the level risk to traffic safety and roadside hazards. A good design must be based on reliable speed data. Once a hazard that requires treatment is identified, it may have to be removed, moved or mitigated through engineering solutions other than safety barriers. Road safety devices cannot be treated as elements of traffic layout and considered at the last stage of the design when safe solutions can no longer be applied.

\section{Overview of Polish guidelines}

The document "Guidelines for safety barriers on national roads" sets out the requirements for national roads. The guidelines of the General Directorate for National Roads and Motorways (GDDKiA) are mandatory on roads managed by the GDDKiA. Where regional, county and municipal roads are concerned, these requirements are optional [1].

The legal status of the GDDKIA guidelines is a different topic. The term "guidelines" does not exist in Polish legislation. Instead, another term is used, i.e. the national notified application appendix (which means that it is approved by the EU) to a harmonised standard. As a result, guidelines should be presented as an appendix to the EN 1317 standard approved by the EU. This ensures that a specific product meets the requirements and can be used on specific types of roads in a country. The current guidelines, however, can take the form of Director General decisions and will only apply to national roads.

GDDKiA guidelines do not explain how to select the following restraints and their parameters: crash cushions, support structures, anti-glare screens, safety barrier terminals, transitions and temporary safety barriers, pedestrian guardrails, motorcyclist restraints and culvert covers.

To ensure that road and roadside hazards can be assessed objectively, their effect on the safety of road users, third parties and objects is properly understood and the right restraints for the hazards identified are designed, the guidelines distinguish between areas at risk and obstacles. Risk areas are defined by the severity of risk and the distance between the hazard and edge of road.

Safety barriers are selected using diagrams that help to determine the containment level of a particular case. The basic data to be input into the diagram include:

- the severity of the hazard which depends on the distance between the zone protected or obstacle and the road; four levels are identified and the distances are read from nomograms depending on the speed and type of road,

- reference speed - a new term used for the purposes of the guidelines, it is equal to operating speed for road category A, S, GP and Z in accordance with the technical and construction regulations for public roads; for class $Z$ roads it is the lower of two values: allowed speed $+10 \mathrm{~km} / \mathrm{h}$ or design speed $+10 \mathrm{~km} / \mathrm{h}$, for roads in built-up areas and ramps and interchanges - allowed speed $+10 \mathrm{~km} / \mathrm{h}$,

- average daily volume of heavy goods vehicles.

To determine barrier containment the designer must answer a number of additional questions. For every barrier adequate distance must be assured from the protected space or area of risk which is to be greater than or equal to the working width. In the case of water reservoirs or slopes, a higher level is acceptable (i.e.W6 rather than W5). As a result, shoulders and bridge plates must be widened, especially because the wheel of a vehicle must not drive off the edge of the structure in case of a crash.

Where a road section includes safety barriers of varying containment levels spaced at short distances, it is recommended to use transition barriers. The containment parameters of these transitions depend on the parameters of the barriers they connect. Unfortunately, the guidelines do not provide precise definitions or examples. As a result, when the designs are prepared by two different organisations, the road/bridge interface may consist of an end of a 
road barrier and the beginning of a bridge barrier (or the other way round) where it should have a transition section.

The guidelines do not provide any rules for how to select barriers on treated roads, if the width of dividing lanes or the proximity to bridge supports makes it impossible to follow the guidelines. Neither is there anything on how to secure road works.

Another problem is the scope of barrier application. There are no guidelines for the road network except the national roads. The region of Silesia is an exception because it has developed its own set of rules [2].

It should be stressed that the guidelines do not take account of the changes in the revised standard PN-EN 1317 [3,4] (e.g. level of vehicle intrusion VI, dynamic deflection D and levels of containment L1, L2, L3, L4a, L4b) because it was published in September 2010, i.e. 5 months after the Polish guidelines were published.

\section{Overview of international guidelines}

Following an analysis of guidelines and standards from nearly forty countries, similarities and differences between the countries were identified. Some countries developed their own guidelines while others have adapted existing solutions to varying degrees (Poland's guidelines are an example because they are based on German guidelines) [5]. Figure 1 shows how the main actors (USA, Australia, Germany) have influenced the geographical scope of the rules.
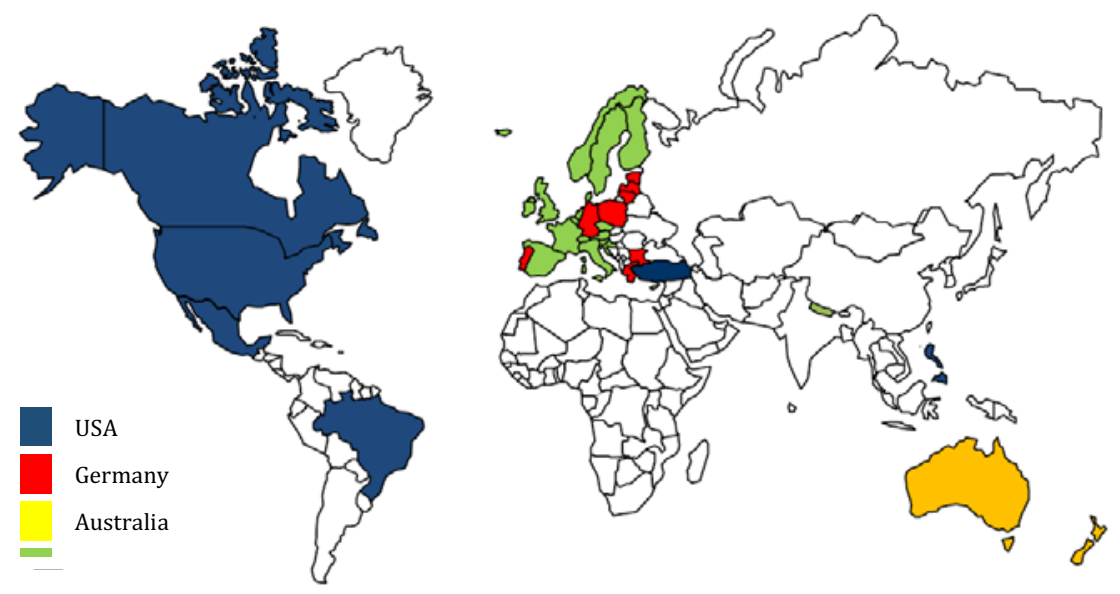

Fig. 1. Distribution of National Guidelines in Other Countries [5].

As we can see, some guidelines / standards dominate in different parts of the world. This goes back to different standards for testing road restraints which are the basis for the guidelines. Standard EN1317 is Europe's VRS test standard (vehicle restraint system), while the US follows the NCHRP350 [6] and MASH [7]. As we can see, American countries have adopted US standards, central Europe uses German standards and northern and western Europe countries have developed their own rules. Despite that, the guidelines have a number of shared solutions such as decision-making processes, tables or charts.

The parameters that determine the type of restraints to be used are divided into thematic groups. Two main categories are distinguished based on the theory of risk: probability and consequences. The probability category includes factors which, if present in a road crosssection, increase the probability of an event. The consequences include factors that increase the severity and consequences of an accident $[8,9]$. 
The charts in Fig. 2 - Fig. 6 show the percentage distribution of factors that determine the use of safety barriers in the particular countries. The percentages represent the number of countries that consider a specific parameter when designing and installing safety barriers [10-12].

\section{Groups of factors}

$0 \% \quad 10 \%$ 20\% 30\% 40\% 50\% 60\% 70\% 80\% 90\% $100 \%$

I - presence of special "third party" risk

II - obstacles posing a risk to road users

$$
\begin{array}{r}
\text { A - traffic } \\
\text { B - speed } \\
\text { C- geometry } \\
\text { D- road layout } \\
\text { E- accidents }
\end{array}
$$

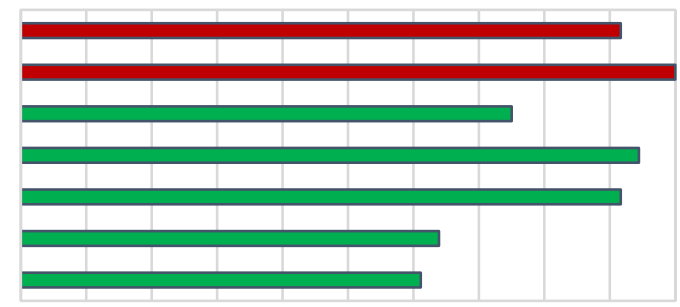

Fig. 2 Groups of factors considered when designing safety barriers based on international guidelines.

\section{I - presence of special "third party" risk}

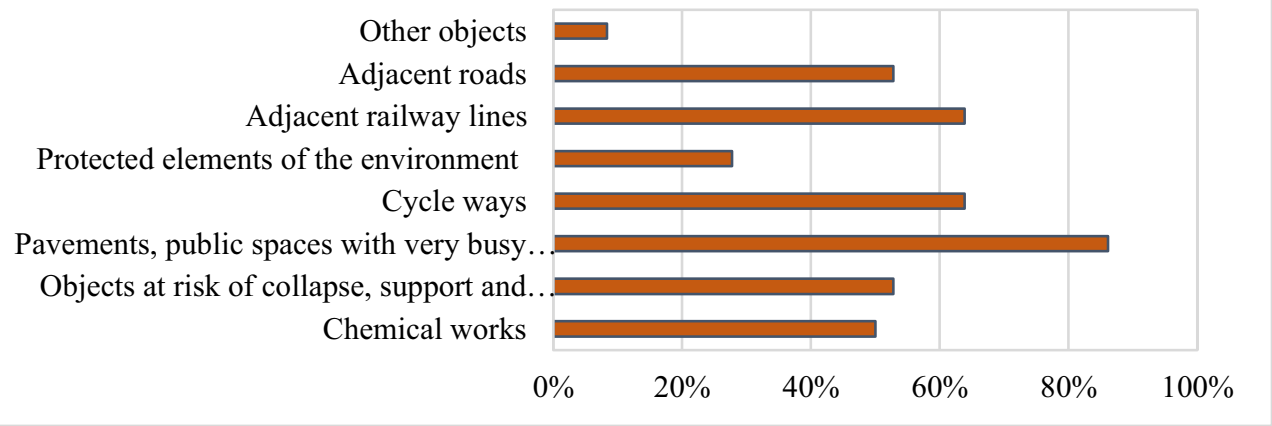

Fig. 3 Groups of factors that pose a hazard to third parties.

\section{II - obstacles posing a risk to road users}

Permanent water reservoirs

Slopes of a trench

Slopes of an embankment

High altitudes (bridges, retaining walls)

Non-deformable point objects

Non-deformable linear objects located..

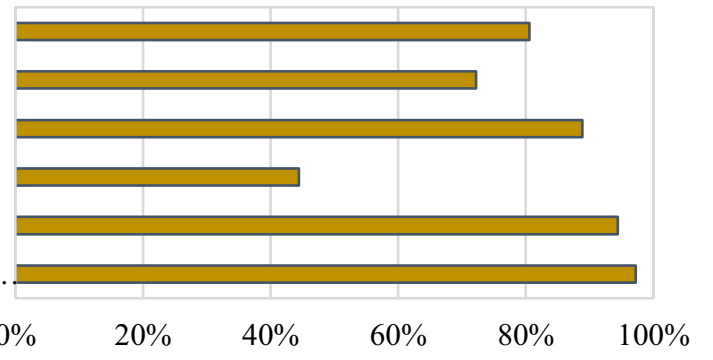

Fig. 4 Groups of factors that pose a hazard to vehicles. 


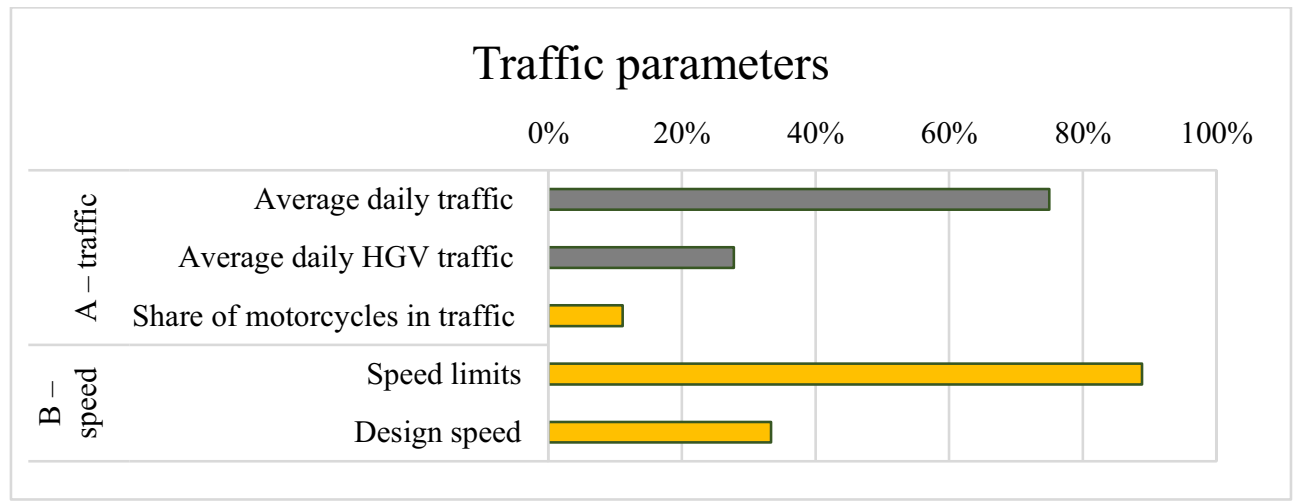

Fig. 5 Traffic conditions for which safety barriers are designed based on international guidelines.

\section{C - road geometry}

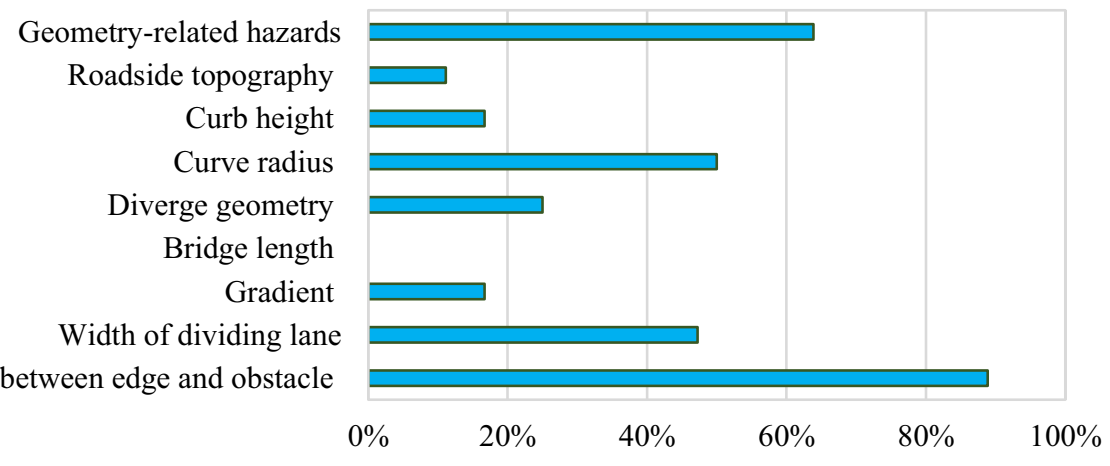

Fig. 6 Geometric conditions for which safety barriers are designed based on international guidelines.

Groups of factors can be identified for how frequently they are used in the analysed guidelines. This can further be used when drafting new guidelines for road restraints system design and application in Poland.

\section{Proposed steps}

Some early work has been done to develop new guidelines for the design and use of road restraint systems. This was based on a review of guidelines and principles used in other countries, the PN 1317 standard, national roads regulations and comments to 2014 guidelines (which were never implemented). The new guidelines would consist of three parts:

- part one - safety barrier guidelines (for new designs, treated roads, improved roads)

- part two - barriers introduced prior to standard PN EN-1317 and temporary barriers (existing roads, road works)

- part three - appendices (symbols and definitions, examples of calculations, catalogue of selected solutions)

Part one will include the following chapters:

- calculating the safety zone

- criteria for using road safety barriers

- criteria for using bridge barriers 
- criteria for using transitions, beginnings and ends, barrier gaps and safety elements other than barriers.

Further research will focus on site tests and numerical tests, their analysis and the development of road safety models taking account of roadsides and road safety devices.

\section{Acknowledgements}

This article was written as part the research project RID 3A - Road safety elements (OT3-3A/PG), funded by the National Centre for Research and Development and the General Directorate for National Roads and Motorways (GDDKiA).

\section{References}

1. Guidelines for the use of road safety barriers on national roads (GDDKiA, Warsaw, 2010)

2. Design Guidelines for the use of road barriers on regional roads (Road Administration Board in Katowice, 2012)

3. Polish Standard PN-EN 1317-1 Road restraint systems, Part 1: Terminology and general criteria for test methods, (2010)

4. Polish Standard PN-EN 1317-2 Road restraint systems, Part 2: Performance classes, impact test acceptance criteria and test methods for safety barriers (2010)

5. F. La Torre, SAVeRS Selection of Appropriate Vehicle Restraint Systems, (2014)

6. NCHRP 350 Recommended Procedures for the Safety Performance Evaluation of Highway Features (Transportation Research Board, 1992)

7. Manual for Assessing Safety Hardware (American Association of State Highway and Transportation Officials, 2009)

8. M. Budzyński, K. Jamroz, Ł. Jeliński, M. Antoniuk, Why are trees still such a major hazard to drivers in Poland?, Transp. Res. Procedia. 14 (2016)

9. K. Jamroz, M. Budzyński, W. Kustra, L. Michalski, S. Gaca, Tools for road infrastructure safety management - Polish experiences, in: Transp. Res. Procedia, pp. 730-739 (2014). doi:10.1016/j.trpro.2014.10.052

10. Road Safety Barriers - Design Guide Part A (Australian Department of Infrastructure Energy and Resources, n.d.)

11. Road Safety Barriers - Design Guide Part B (Australian Department of Infrastructure Energy and Resources, n.d.)

12. A Strategic Road. Technical report (2015) 